\title{
Detection of Microorganisms Onboard the International Space Station Using an Electronic Nose
}

\author{
Ulrich Reidt ${ }^{5}$, Andreas Helwig ${ }^{1}$, Gerhard Müller ${ }^{1}$, Lutz Plobner $^{2}$, Veronika Lugmayr ${ }^{2}$, Sergey Kharin ${ }^{3}$, \\ Yuri Smirnov ${ }^{3}$, Natalia Novikova ${ }^{3}$, Joachim Lenic ${ }^{4}$, Viktor Fetter ${ }^{5}$, and Thomas Hummel ${ }^{5}$
}

\begin{abstract}
${ }^{1}$ Airbus Group Innovations, Airbus Central R\&T, XRXG - Materials, Munich, Germany; ${ }^{2}$ Agrobiogen GmbH, Hilgertshausen, Germany; ${ }^{3}$ State Scientific Center of the Russian Federation - Institute of Biomedical Problems (IBMP) of the Russian Academy of Sciences, Moscow, Russia; ${ }^{4}$ Deutsches Zentrum für Luft- und Raumfahrt (DLR), Bonn, Germany; ${ }^{5}$ Airbus Defence and Space GmbH - Space Systems, Dept. TESXS Science Engineering, Friedrichshafen, Germany
\end{abstract}

\begin{abstract}
We report on the detection of microorganisms onboard the International Space Station (ISS) using an electronic nose we named the E-Nose. The E-Nose, containing an array of ten different metal oxide gas sensors, was trained on Earth to detect the four most abundant microorganisms that are known to exist onboard the ISS. To assess its performance in space, the E-Nose was brought to the ISS and three measurement campaigns were carried out in three different locations inside the ISS during a 5-month mission. At the end of this mission, all investigated locations were wiped with swabs, and the swabs and odor sensor signal data were sent back to Earth for an in-depth analysis in earthbound laboratories. The in-space measurements were compared with an odor database containing four organisms, but a
\end{abstract}

Key words: International Space Station (ISS);

Spaceflight; Electronic Nose; Yeast;

Rhodotorula mucilaginosa; Microorganism

Correspondence to: Ulrich Reidt

Airbus Defence and Space GmbH,

Dept. TESXS Science Engineering

D-88039 Friedrichshafen, Germany

Telephone: +49 (0) 7545 8-7123

E-mail: ulrich.reidt@airbus.com consensus odor could not be identified. Microbiological results could not provide clues to the smell that was measured. The yeast Rhodotorula mucilaginosa was identified in the literature as the most probable candidate for the unknown odor. Further investigations showed that the smell of Rhodotorula mucilaginosa matches very well with the data obtained inside the ISS. Finally, Rhodotorula mucilaginosa DNA was identified in swabs taken from the sleeping cabin of the astronaut, which confirms the assumption that the yeast Rhodotorula mucilaginosa was actually measured in space by the E-Nose.

\section{INTRODUCTION}

The International Space Station (ISS) is one of the largest technology projects and the "outpost" of humanity in space. Furthermore, the ISS is a flying laboratory with excellent opportunities for scientific and industrial research in the hostile space environment. It is still a great challenge to ensure the continuous survival of the ISS crew in space. The main component for sustaining life in orbit is the Environmental Control and Life Support System (ECLSS) at ISS, which generates optimal conditions for the crew in this closed habitat. With the help of the ECLSS, the temperature inside the ISS is maintained 
within a range of $18-28^{\circ} \mathrm{C}$ and the relative humidity from $30-70 \%$ (Prokhorov, 2009). These conditions, which are optimal for sustaining human life in space, unfortunately are also optimal for microorganisms. The most influential parameters for the spreading of bacteria and fungi are warm temperature, high humidity, and sufficient carbon sources. Because these conditions do exist inside the ISS, it is not surprising that bacteria and fungi can grow and spread very well within the space station. Obviously, living in a closed, contaminated environment presents a significant health risk for crews on long space missions (Pierson, 2001). Therefore, it is clear that a clean environment is required to reduce the health risks to astronauts, particularly during long missions, such as travel to Mars. For this reason, it is essential to detect biological contaminants at an early stage and to avoid their growth.

In the year 2000, a new era in crewed spaceflight began with the permanent habitation of the ISS. During the commissioning of the station, bacteria and fungi also travelled as socalled "blind passengers" to the space station. The origin of this colonization and the most evident contamination sources were the astronauts themselves. It was reported that microorganisms mainly came from the skin, mucous membranes, upper respiratory tract, mouth, nasal passages, and gastrointestinal tract (Novikova et al., 2006). Normally, most of these human commensals do not represent any serious hazard to human health; however, in some immunosuppressed individuals, such as astronauts on long space missions, these seemingly harmless organisms can trigger diseases or allergies. A further concern for the safety of the crew is the biodegradation of materials by microorganisms. Results from the Mir space station indicate that biologically induced corrosion and biodeterioration of materials is a serious problem. It was shown that bacteria and fungi can degrade and destroy structural materials such as metals and polymers (Viktorov et al., 1992; Klintworth et al., 1999).

To determine the microbiological load onboard the ISS and possible countermeasures, the microbiological load is currently collected by swabs, contact plates, and air samplers including culture plates (Novikova et al., 2006). For an indepth analysis, these items need to be brought back to Earth for investigation in earthbound laboratories. In the future, it would be a significant step forward to have an easy-to-use, hand-held, portable instrument capable of realtime onboard detection using a label-free method. Microbiological assays are typically performed in liquids, which is challenging under microgravity conditions. Therefore, a water-independent detection system would be a better choice for onboard measurements than performing conventional tests such as polymerase chain reaction (PCR), enzyme-linked immunosorbent assay (ELISA), or API. A type of analysis system that can comply with most of these requirements is the electronic noses. The great advantage of electronic noses is that these perform label-free assays without any liquids, and provide measurements in almost real-time. Because of these features, electronic noses appear to be perfect detector system candidates for space use.

Currently, an electronic nose is in use for the purpose of environmental monitoring inside the US Lab on the ISS. This Jet Propulsion Laboratory (JPL) Electronic Nose system is commonly utilized for air monitoring to detect and identify gaseous components such as formaldehyde, ammonia, mercury, and sulfur dioxide (Ryan et al., 2009). This electronic nose, however, has not yet been used for the detection of microbial volatile organic compounds (MVOCs). MVOCs are produced by bacteria and fungi during their growth and often give rise to very noticeable smells such as "moldy" odors. Typical compounds emitted by microorganisms include hydrocarbons such as octane and 1octene, terpenes such as isoprene and geosmin, alcohols, carboxylic acids, esters, and sulfur derivatives (Wilkins et al., 2000; Korpi et al., 1998). Because the mixtures of MVOCs are characteristic of specific bacteria or fungi, these molecules are perfect candidates for the detection and identification of microorganisms by electronic noses. Previously, an electronic nose named the MonoNose was used for the identification of several pathogenic bacterial species from clinical samples. The identification of MVOCs with this electronic nose was nearly real-time and successfully differentiated several different bacterial species such as Escherichia coli, Klebsiella oxytoca, Staphylococcus aureus, Enterococcus faecalis, and Pseudomonas 


\section{Reidt et al. -- Electric Nose Detects Microorganisms on ISS}

aeruginosa (Bruins et al., 2009). Another electronic nose used for the detection and identification of microorganisms is the Cyranose 320. This system can detect S. aureus, Haemophilus influenzae, Streptococcus pneumonia, Moraxella catarrhalis, and the two most common bacteria species of Escherichia coli and P. aeruginosa (Dutta et al., 2002). In both cases, principal component analysis (PCA) of the sensor signals provided distinguishable data clusters characteristic of individual bacterial strains, which demonstrates the potential of electronic noses for the detection and identification of microorganisms.

In this article we report on the detection and identification of microbiological contamination inside the Zvezda Service Module, which is part of the Russian segment of the ISS, using an electronic nose called the E-Nose. This E-Nose, which contains ten different kinds of metal oxide (MOX) gas sensors, was trained on Earth to detect the four most abundant microorganisms known to exist onboard the ISS (Novikova et al., 2009). The E-Nose was launched in December 2012 to the ISS and used in three campaigns stretching over a period of 135 days, focusing on three locations: working table, sleeping cabin, and toilet lid. The results were saved on a memory card that was brought back to Earth together with three swabs (Q-tips Q1-Q3) that were used to wipe the three locations after the end of the last measurement campaign. Back on Earth, the sensor data were analyzed with the help of chemometric software and the obtained data sets were compared to those that had been generated by the four microorganisms that constituted the original training set (Bacillus subtilis, Staphylococcus warneri, Penicillium expansum, Aspergillus versicolor). In parallel, the swabs were analyzed by a full range of standard microbiological analysis methods to assess the sensor performance of our E-Nose.

\section{MATERIALS AND METHODS}

\section{Creation of the Odor Database and Cultivation of Microorganisms}

To build an MVOC database, two bacteria and two fungi were selected that were known to be present onboard the ISS. The bacterial strains
B. subtilis (DSM No.: 1088) and S. warneri (DSM No.: 20316) as well the fungal strains $P$. expansum (DSM No.: 1282) and A. versicolor (DSM No.: 1943) were first cultivated from a freeze-dried stock culture obtained from the Leibniz Institut DSMZ-Deutsche Sammlung von Mikroorganismen und Zellkulturen $\mathrm{GmbH}$ in Braunschweig, Germany. After this, both bacterial strains were cultivated with tryptic soy broth medium and fungal strains were grown on Czapek-Dox agar and Czapek-Dox broth medium received from Sigma-Aldrich Chemie $\mathrm{GmbH}$, Munich, Germany. For all media, the dehydrated powder was suspended in 1 liter of distilled water and sterilized at $121^{\circ} \mathrm{C}$ for $15 \mathrm{~min}$. After sterilization and cooling to $45-50^{\circ} \mathrm{C}$, the media were poured into Petri dishes. For gas-sensing experiments, 2 to $5 \mathrm{~mL}$ of each culture medium was transferred to mini Petri dishes. Subsequently, the mini Petri dishes were placed into custombuilt gas vessels that allowed the cultures to grow under controlled gaseous conditions inside a cultivation station (Figure 1). To ensure identical growth conditions for all cultures, a constant flow of 20-30 L/min of humidified synthetic air (relative humidity, 70-90\%) was guided through all mini Petri dishes. Additionally, some of the cultures were grown on materials that are used inside the ISS; identically sized samples of sterilized materials including Nomex, cable marker, aluminum, and printed circuit board (PCB) material were added to the cultures. After inoculation, all cultures were cultivated at an ambient temperature of $20^{\circ} \mathrm{C}$, over periods of time ranging from $24 \mathrm{~h}$ to 14 days. As these cultures progressed through different growth phases, samples were taken for measurements with the ENose. After E-Nose measurements, random samples were taken only from the bacterial samples to measure bacteria cell concentrations in terms of colony forming units (CFU). Lower bacterial cell concentrations were obtained by drying the cultures inside the cultivation station, leading to selectively dehydrated cultures. During this drying procedure, the CFUs decreased progressively. To determine the concentration from a dried culture, $1 \mathrm{~mL}$ of sterile water was added to the mini Petri dish containing the dried culture and the encrustation was dissolved to form a homogeneous solution. Thereafter, these 
A

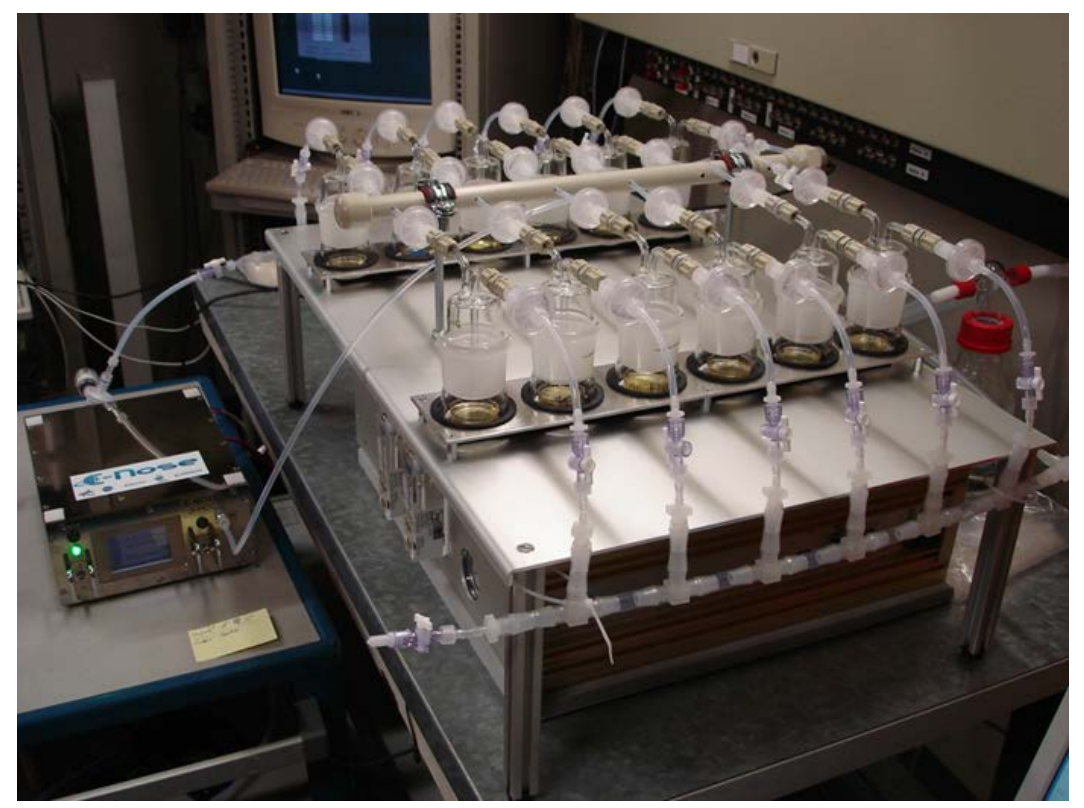

B

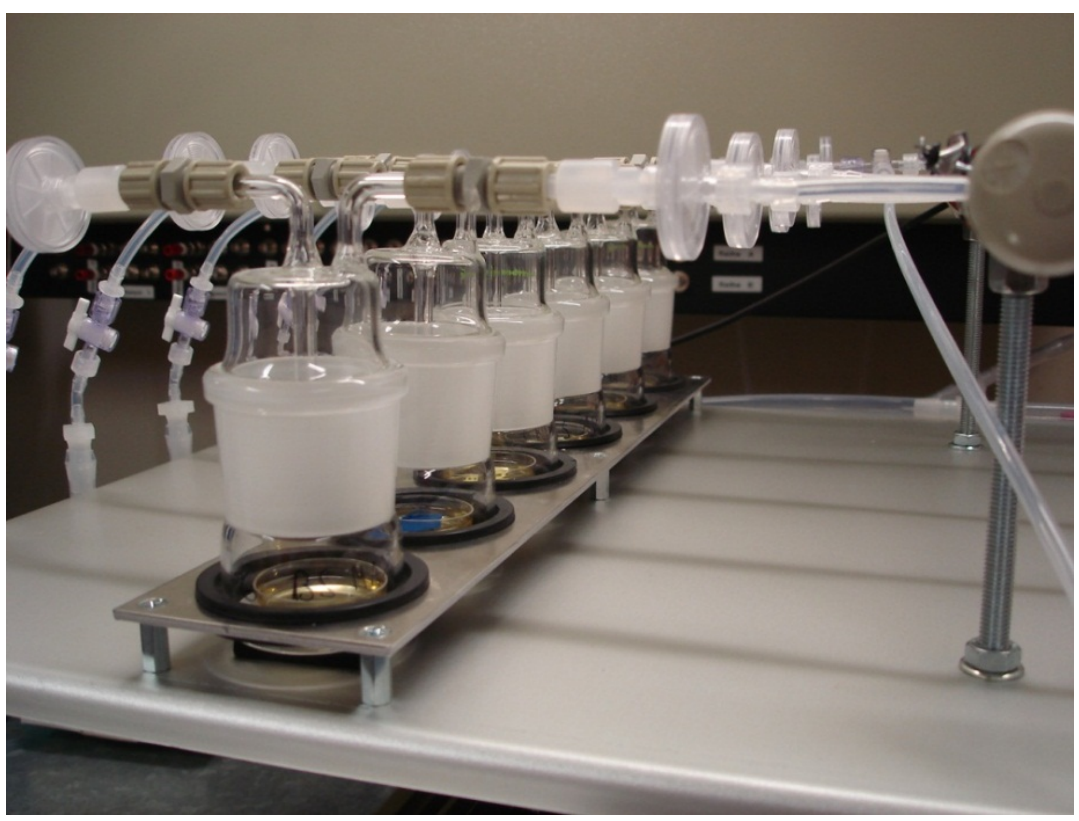

Figure 1. (A) Cultivation station with 12 custom-built gas vessels in which the organisms are grown under controlled gaseous environments. The E-Nose is connected on the left for measurement of the cultures. (B) Gas vessels with the culture of Bacillus subtilis in liquid tryptic soy broth media.

cultures were processed as normal liquid bacterial cultures. For liquid bacterial cultures, a dilution series was made up to a dilution of $1: 10^{6}$, and 100 $\mu \mathrm{L}$ from each dilution was streaked onto tryptic soy agar (TSA). The culture plates were incubated at $30-37^{\circ} \mathrm{C}$ overnight and the number of CFUs was determined at the end of the incubation time.

\section{Design of E-Nose, Air Sampler, and Target} Book

The E-Nose used for the experiments was primarily manufactured by Airsense Analytics $\mathrm{GmbH}$, Germany and specifically modified for the intended space application (Figure 2). The system has a dimension of $248 \times 196 \mathrm{~mm}$ and consists of a 
A

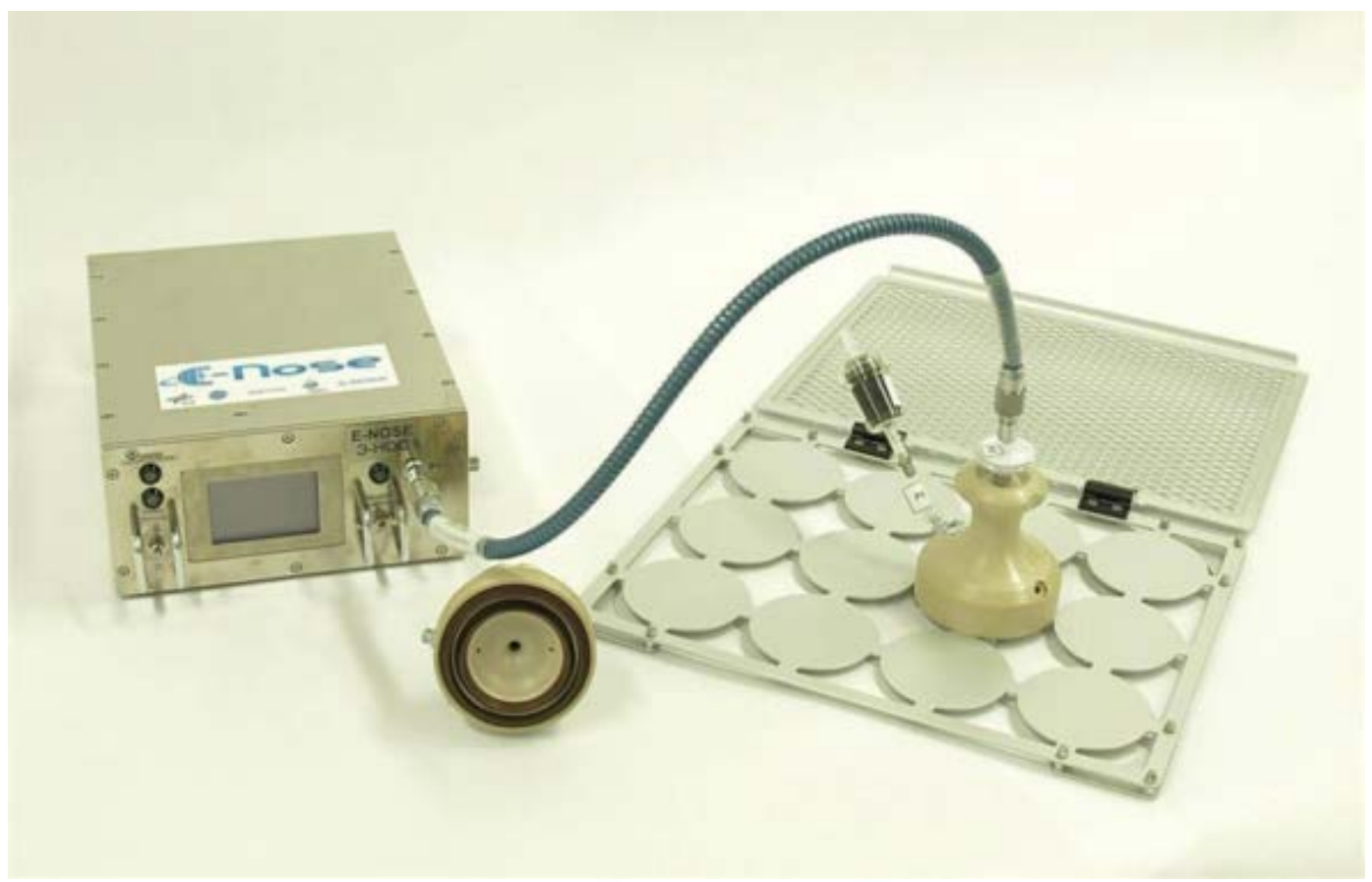

B

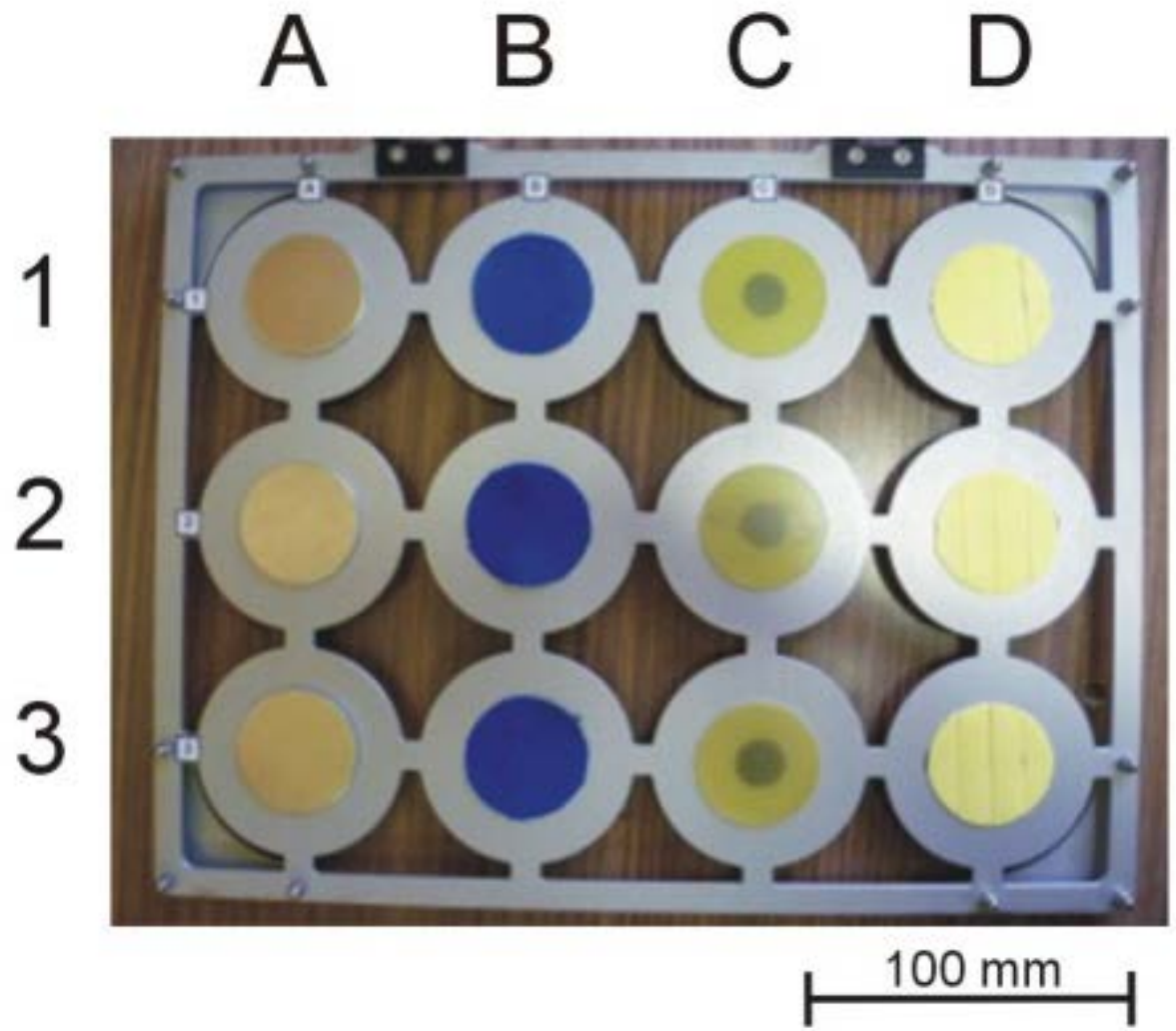

Figure 2. Illustration of the E-Nose and the Target Book that were used for experiments at the ISS. (A) The E-Nose is connected with an air sampler via a transfer line. Attached to the air sampler is a charcoal filter. Figure (B) The Target Book with four different materials: A1-A3, non-anodized aluminum; B1-B3, Nomex; C1-C3, printed circuit board material; and D1-D3, cable labeling material. 


\section{Reidt et al. -- Electric Nose Detects Microorganisms on ISS}

sensor array with ten different kinds of MOX gas sensors produced by UST, Germany. During measurement, the sensitive layers of the sensors are exposed to volatile organic compounds and the resulting changes in the sensing layer resistances are monitored and recorded as sensor signals. Depending on the compounds measured, the ten sensor signals form patterns, which are characteristic of the specific bacteria or fungi present. The MVOCs originating from the bacterial and fungal species were collected through a custom-built air sampler and a tubular transfer line. As shown in Figure 2A, the air sampler consists of a hollow plastic chamber with an internal volume of $19 \mathrm{~cm}^{3}$ and an internal diameter of $80 \mathrm{~mm}$, which can be placed over the sample plates that carry the bacteria or fungal samples. Two O-ring seals at the bottom of the air sampler ensure an air-tight contact to the sample plates and allow controlled airflow to be guided through the head space formed by the air sampler. To enable controlled flows of reference and sample air, the air sampler was fitted with two valves. The inlet valve, which is open during the gas sampling phase, allows ambient air to be drawn through a charcoal absorber into the air sampler's head space and into the E-Nose. To avoid any microbiological contamination of the sensor array, a sterile filter was inserted into the transfer line. The outlet valve on the air sampler is opened only during reference measurements and allows purified reference air coming from the ENose and guided through the air sampler's head space to be ejected back into the ambient air. For the assessment of MVOC patterns, the E-Nose was operated in two alternating phases. During the cleaning phase, ambient air was sucked through the backside inlet of the E-Nose and through a charcoal absorber to produce a stream of zero air. This reference air was guided over the MOX sensor array through the transfer line and the outlet valve of the air sampler to establish a set of reproducible sensor baseline signals. During the sampling phase, the air flow through the E-Nose system was reversed and ambient air was sucked through the charcoal filter mounted upstream of the air sampler's entrance port through the air sampler's head space towards the MOX sensor array. In this latter operation mode, any MVOCs that were produced by microorganisms were carried to the MOX sensor array.
For negative control measurements, a so called Target Book was also launched to the ISS. The Target Book was composed of aluminum and the dimensions were $325 \mathrm{~mm} \times 255 \mathrm{~mm}$. It contained 12 round targets composed of 4 different substrate materials, each with a diameter of $40 \mathrm{~mm}$ and a surface area of $12.56 \mathrm{~cm}^{2}$. All substrates were covered by a coarse-meshed grid with a pore size of $0.7 \times 0.7 \mathrm{~mm}^{2}$ to prevent any accidental touching of the targets. The materials were successively attached at positions as follows: A1-A3 non-anodized aluminum; B1-B3 Nomex, a special flameresistant aramid polymer tissue; C1-C3 PCB material; and D1-D3 a polyimide cable labeling material (Figure 2B). All four materials were selected based on original materials used within the ISS. The materials on the Target Book were first sterilized with $3 \%$ hydrogen peroxide for $15 \mathrm{~min}$ and then by exposure to UV light for $30 \mathrm{~min}$. At the end of the sterilization procedure, the Target Book was packed under sterile conditions for transport to the ISS. The Target Book was used as a negative control and it was placed for further experiments within the Zvezda Service Module in the Russian segment of the ISS for 135 days (Reidt et al., 2014).

\section{Training of Cosmonauts and E-Nose Measurements under Microgravity at ISS}

Before spaceflight, cosmonaut Roman Romanenko was trained to handle the equipment in a mock-up of the ISS Zvezda Service Module at Star City, Russia. Assembly and operation of the E-Nose were trained in detail using a checklist (Figure 3). After launch and docking of the Soyuz TMA-07M space capsule to the ISS, commissioning (initial examination of correct function) was performed and gas measurements were started with the air sampler connected to the transfer line followed by a standard E-Nose measurement setup. The sampling frequency was set to one sample per second. Sensor cleaning was performed for $300 \mathrm{~s}$ and the length of the sampling period was fixed at $300 \mathrm{~s}$. The air flow during the sensor cleaning and sampling phase was set to 400 standard cubic centimeters per minute without any dilution flow during the sampling phase. During measurement at each of the three locations (i.e., working table, sleeping cabin, toilet lid), a set of 300 data points was 


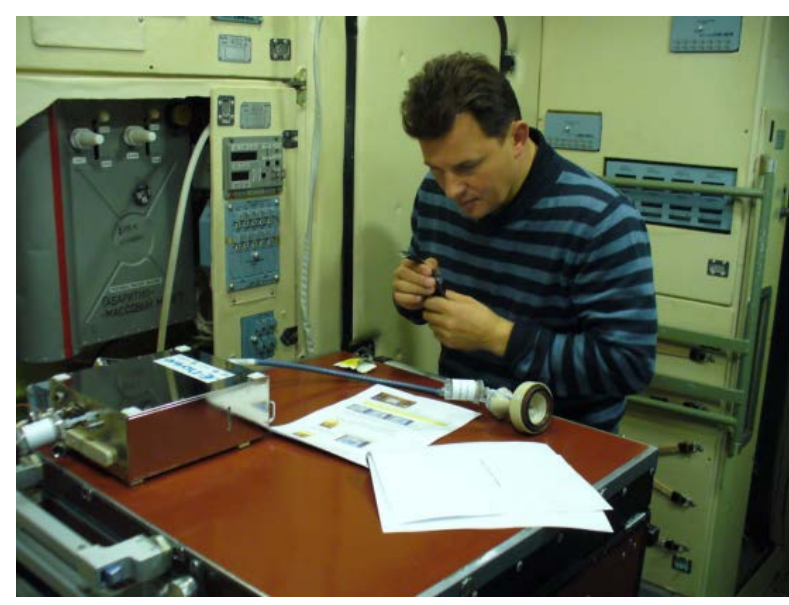

Figure 3. Training of cosmonaut Roman Romanenko in the mock-up of the Zvezda Service Module at Star City, Russia.

collected starting at the moment of adjustment of the air sampler to the measurement location. Finally, all data were saved on a memory card connected to the E-Nose.

\section{Surface Sampling at ISS}

After the last measurements with the E-Nose, the surfaces were swabbed with three Q-Tip-style cotton swabs (Q1, working table; Q2, sleeping cabin; Q3, toilet lid). For each location, a surface area of $100 \mathrm{~cm}^{2}$ was swabbed in a meander fashion by a rolling motion of the swab. All three swabs were made in-house at the Institute of Biomedical Problems (IBMP), Russia. The Surface Pipette Kit consists of a soft transport bag with several pockets including plastic tubing where swabs were inserted. All cotton swabs were impregnated in $100 \mathrm{mM}$ sterile phosphate buffer, pH 7.0 (Figure 4).

\section{E-Nose Data Processing}

At the end of the space mission, the memory card with all data files was transported to Earth. Raw data were analyzed and evaluated with the software Origin from OriginLab Corporation, USA. The data were processed by the software MATLAB from MathWorks Corporation, USA. Final representation of the data was performed using PCA by the software PLS_Toolbox (for MATLAB), obtained from Eigenvector Research Incorporated, USA.

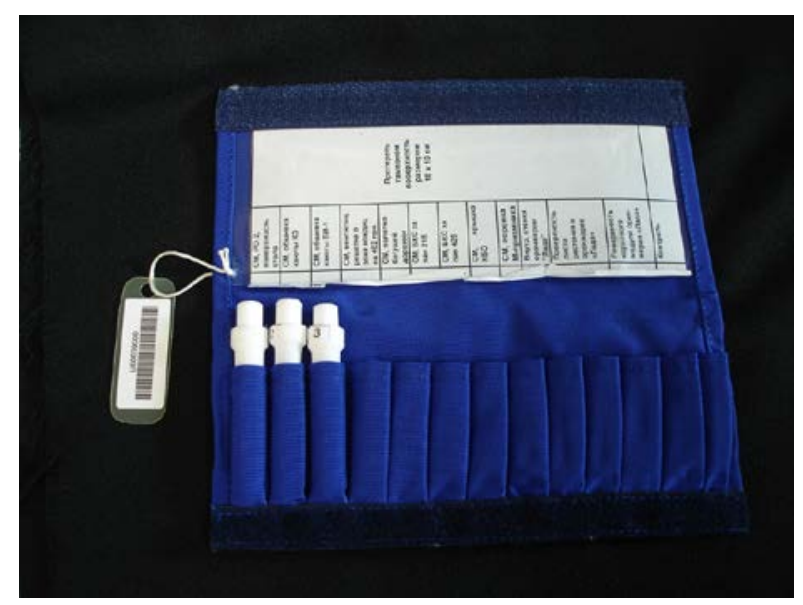

Figure 4. Surface Pipette Kit used for swabbing the surfaces of the three locations of measurements. Cotton swabs (Q-tip style) from left to right: Q1: working table, Q2: sleeping cabin, and Q3: toilet lid.

\section{Processing of Biological Samples from ISS and Cultivation of Microorganisms}

Media were obtained from Sigma-Aldrich and Carl Roth, Germany and were prepared according to the formula of R2A agar (R2A), tryptone soya agar (TSA), yeast extract agar (YEA), MacConkey agar, mannitol salt agar (MSA), yeast extract peptone dextrose agar (YEPD), and Sabouraud 4\% glucose agar (SGA) (Digestive Ferments Company, Difco Laboratories, 1953). The dehydrated powder from each medium was suspended in 1 liter of distilled water and sterilized at $121^{\circ} \mathrm{C}$ for $15 \mathrm{~min}$. After sterilization and cooling to $45-50^{\circ} \mathrm{C}$, the media were poured into Petri dishes. After preparation of the culture plates, swabs from the ISS were washed out in 1 $\mathrm{mL}$ sterile $0.85 \% \mathrm{NaCl}(\mathrm{w} / \mathrm{v})$ and dilution series ranging to $1: 1000$ were produced from each swabbed target. The remaining undiluted wash solution was stored at $-87^{\circ} \mathrm{C}$ as a backup. Next, $100 \mu \mathrm{L}$ of each dilution was streaked on the different culture plates, and all plates were incubated at $20^{\circ} \mathrm{C}$ for 5 to 10 days. After incubation, numbers of CFU were determined by examination of the culture plates. To obtain pure cultures, 25 selected colonies were picked from the agar plates under laminar flow with a sterile inoculation loop to produce the same number of pure cultures. After streaking the picked colonies, the culture plates were incubated at the same conditions used for CFU determination. 


\section{Extraction of DNA from Pure Cultures}

Cells from all pure cultures were transferred with an inoculation loop to appropriately labeled tubes with lysis buffer from the nexttec ${ }^{\mathrm{TM}} 1$-Step DNA Isolation Kit for Bacteria obtained from Agrobiogen GmbH, Germany. For bacteria, the lysis and DNA purification were carried out according to the protocol of the nexttec ${ }^{\mathrm{TM}}$ kit for bacteria. After enzymatic lysis, the genomic DNA was purified with special spin columns (nexttec ${ }^{\mathrm{TM}}$ cleanColumns). For fungi, the protocol of the nexttec $^{\text {TM }}$ 1-Step DNA Isolation Kit for Tissue \& Cells was modified. Enzymatic lysis was combined with upstream mechanical disruption. The mechanical disruption was performed in a reaction tube with glass beads $(\mathrm{d}=0.5-0.75 \mathrm{~mm})$ by shaking in a high-frequency 3D RibolyserTM from Hybaid, Germany for $15 \mathrm{~s}$ at a speed of 4 $\mathrm{m} / \mathrm{s}$. After mechanical lysis, samples were further lysed enzymatically and DNA was purified by nexttec ${ }^{\mathrm{TM}}$ cleanColumns as described in the protocol of the nexttec ${ }^{\mathrm{TM}}$ 1-Step DNA Isolation Kit for Tissue \& Cells.

\section{Direct DNA Extraction from Washout of Surface Samples Q1, Q2, and Q3}

Direct DNA isolation from frozen swab washout was performed by a modified nexttec ${ }^{\mathrm{TM}}$ 1-Step DNA Isolation Kit for Tissue and Cells. The enzymatic lysis applied in the nexttec ${ }^{\mathrm{TM}}$ protocol was combined with mechanical lysis. Specifically, the swabs stored in $0.9 \%$ sterile saline solution were centrifuged in spin baskets for $1 \mathrm{~min}$ at $8000 \mathrm{rpm}$. A flow-through volume of $200 \mu \mathrm{L}$ was transferred to a reaction tube with glass beads $(\mathrm{d}=0.5-0.75 \mathrm{~mm})$ and processed in the 3D Ribolyser ${ }^{\mathrm{TM}}$ and the nexttec ${ }^{\mathrm{TM}}$ 1-Step DNA Isolation Kit for Tissue \& Cells as described in "Extraction of DNA from Pure Cultures."

\section{Amplification of Bacterial 16S rRNA Gene by Conventional PCR}

The PCR primer pair for bacteria (P3MOD forward: 5'-ATTAGATACCCTDGTAGTCC-3', PC5B reverse: 5'-TACCTTGTTACTT-3') was synthesized by Eurofins MWG Operon, Germany using sequences obtained from the literature (Kuske et al., 1998). PCR mixtures contained 10 $\mathrm{mM}$ Tris- $\mathrm{HCl}(\mathrm{pH} 8.3), 50 \mathrm{mM} \mathrm{KCl}, 1.5 \mathrm{mM}$
$\mathrm{MgCl}_{2}, \quad 2.5 \mathrm{mM}$ each of the four deoxynucleotides, $100 \mathrm{pmol}$ of each primer, 5 $\mathrm{U} / \mu \mathrm{L}$ Taq DNA polymerase (New England Biolabs, USA), and $2 \mu \mathrm{L}$ genomic DNA as template. Negative controls did not contain template DNA. The PCR assays were conducted in a TPersonal thermocycler from Biometra $\mathrm{GmbH}$, Germany, with the following thermal profile: initial denaturation for $5 \mathrm{~min}$ at $95^{\circ} \mathrm{C}$, followed by 30 cycles of denaturation at $95^{\circ} \mathrm{C}$ for $20 \mathrm{~s}$, annealing at $45^{\circ} \mathrm{C}$ for $20 \mathrm{~s}$, and extension at $72^{\circ} \mathrm{C}$ for $1 \mathrm{~min}$, and final extension at $72^{\circ} \mathrm{C}$ for 5 min. The amplified PCR products were separated on a $1.5 \%(\mathrm{w} / \mathrm{v})$ agarose gel and stained with dimidium bromide. Agarose gels were prepared and run in $1 \times$ TAE buffer $(50 \times$ TAE: 242 g Trisbase, $57.1 \mathrm{~mL}$ acetic acid, $100 \mathrm{~mL} 0.5 \mathrm{M}$ EDTA, water to $1000 \mathrm{~mL}, \mathrm{pH} 8.5)$. The PCR products were compared to a $1-\mathrm{kb}$ DNA ladder obtained from New England Biolabs, USA, to estimate their size. The results were scored as positive or negative by visual inspection.

\section{Amplification of Fungal 18S rRNA Gene by Conventional PCR}

The purified DNA from pure fungal cultures and from swab samples were amplified using a common universal PCR primer pair for the $18 \mathrm{~S}$ ribosomal RNA gene of yeasts and other fungi (NS1 Forward: 5'-GTAGTCATATGCTTGTCTC3' and NS2 Reverse: 5'-GGCTGCTGGC ACCAGACTTGC- $3^{\prime}$ ). The primer pair was synthesized by TIB MOLBIOL GmbH, Germany, according to sequences obtained from the literature (White et al.,1990). Final PCR mixtures $(50 \mu \mathrm{L})$ contained $1 \times$ PCR buffer (Genaxxon Bioscience $\mathrm{GmbH}$, Germany), $2.5 \mathrm{mM} \mathrm{MgCl}_{2}$, $200 \mu \mathrm{M}$ each the deoxynucleotides, $15 \mathrm{pmol}$ each primer, 1.5 units Taq DNA polymerase from Dialat Ltd., Russia, and $5 \mu \mathrm{L}$ genomic DNA preparation as a template. Negative controls were mock isolations. As a no template control (NTC), $5 \mu \mathrm{L}$ of pure water was added to the PCR assay. The PCR protocol was conducted in a GeneTouch thermocycler from Bioer, China, with the following thermal profile: initial denaturation for $2 \mathrm{~min}$ at $94^{\circ} \mathrm{C}$, followed by 35 cycles of denaturation at $94^{\circ} \mathrm{C}$ for $30 \mathrm{~s}$, annealing at $55^{\circ} \mathrm{C}$ for $1 \mathrm{~min}$, and extension at $72^{\circ} \mathrm{C}$ for $1 \mathrm{~min}$, and final extension at $72^{\circ} \mathrm{C}$ for 5 min. Amplified PCR 
products were separated on a $2 \%(\mathrm{w} / \mathrm{v})$ agarose gel containing $0.1 \mu \mathrm{g}$ dimidium bromide per $\mathrm{mL}$. Agarose gels were prepared and run in $1 \times$ TAE buffer for $40 \mathrm{~min}$ at $4.5 \mathrm{~V} / \mathrm{cm}$. PCR products were compared to a 50 to 1500 bp DNA ladder obtained from Fermentas, Germany, to estimate their size. Results were scored as positive or negative by visual inspection; the fungal fragment has a size of $555 \mathrm{bp}$.

\section{Identification of Rhodotorula spp. by Real- Time PCR}

For differentiation of Rhodotorula mucilaginosa, a qPCR system was used from Diaz and colleagues (Diaz et al., 2013). For sensitive determination of the yeast, the following primers and probe were used for the TaqMan method: Rhod-muc (forward), 5'-GCGCTTTGTGA TACATTTTC-3'; Rhod-muc (reverse), 5'CCATTATCCATCCCGGAAAA-3'; Rhod-muc (probe), 5'-6FAM-ACAAGTACCGTGAGG GAAAGATGAAAA-BBQ-3'.

All qPCRs were performed in $50 \mu \mathrm{L}$ reaction mixtures comprising $1 \times$ PCR buffer from Genaxxon Bioscience GmbH, Germany, $3 \mathrm{mM}$ $\mathrm{MgCl}_{2}, 200 \mu \mathrm{M}$ of each deoxynucleotide, $20 \mathrm{pmol}$ each primer, 10 pmol probe, 1 unit Taq DNA polymerase obtained from Dialat Ltd., Russia, and $5 \mu \mathrm{L}$ isolated DNA as a template. The initial denaturation was performed at $95^{\circ} \mathrm{C}$ for $3 \mathrm{~min}$, followed by 40 cycles of denaturation at $95^{\circ} \mathrm{C}$ for $15 \mathrm{~s}$ and annealing/ elongation at $60^{\circ} \mathrm{C}$ for $45 \mathrm{~s}$. The qPCRs were run in a real-time cycler Mx3005P from Stratagene, USA.

\section{Sequence Data Analysis and Identification of Microorganisms}

Sequencing of both strands of the obtained PCR products was performed by Eurofins MWG Operon, Germany according to the Sanger method using the same primer pairs as for amplification. The PCR products were purified by the NucleoSpin ${ }^{\circledR}$ Gel and PCR Clean-Up Kit from Macherey-Nagel, Germany. The nucleotide sequences were compared by Basic Local Alignment Search Tool (BLAST) analysis against all reference sequences from the GenBank database, excluding model sequences and environmental sample sequences (Benson et al., 1999).

\section{RESULTS}

\section{E-Nose Measurements at ISS at Three Different Positions}

On December 19, 2012, Soyuz TMA-07M launched from Baikonur Cosmodrome, Kazakhstan to the ISS for expedition 34/35. The crew consisted of Tom Marshburn (USA), Roman Romanenko (Russia), and Chris Hadfield (Canada). The expedition lasted approximately six months. During this mission, the E-Nose, which originated from a research project of the same name, was transported to the ISS. Soyuz TMA$07 \mathrm{M}$ docked at the ISS, and the E-Nose was transported after commissioning to the Zvezda Service Module in the Russian segment of the ISS for olfactory measurements (Figure 5A). During the mission time of 135 days, three measurement campaigns with the E-Nose (first: February 28, 2013; second: April 30, 2013; third: May 11, 2013) were carried out. Each campaign included three separate E-Nose measurements at specific locations in the Zvezda Service Module (Figure 5B): a) the working table of the crew, b) the sleeping cabin of the astronaut, and c) the lid of the toilet (Figure 5C). A negative control Target Book was also transported to the ISS. The Target Book was a sterile platform equipped with four materials that were commonly used at the ISS. After usage of the Target Book as a negative control, the sterile platform was placed at the Zvezda Service Module in the Russian segment of the ISS for additional experiments (Reidt et al., 2014) (Figure 5D). After the end of the third ENose measurement campaign, each of the three locations was swabbed with sterile cotton swabs (Q1-Q3), and the three swabs were returned to Earth with the memory card of the E-Nose that contained the measurement data. After landing, the swabs were immediately removed from the Soyuz capsule, cooled to $4^{\circ} \mathrm{C}$, and transported to the laboratories of the IBMP in Moscow, Russia, for a first inspection. Subsequently, the material was transported to the laboratories of Airbus Group Innovations, Munich, Germany without interruption of the cooling of the swabs. In parallel, the memory card of the E-Nose was also transported to Airbus Group Innovations for a thorough analysis of the gas measurements that were performed in space. After data analysis, it 
A

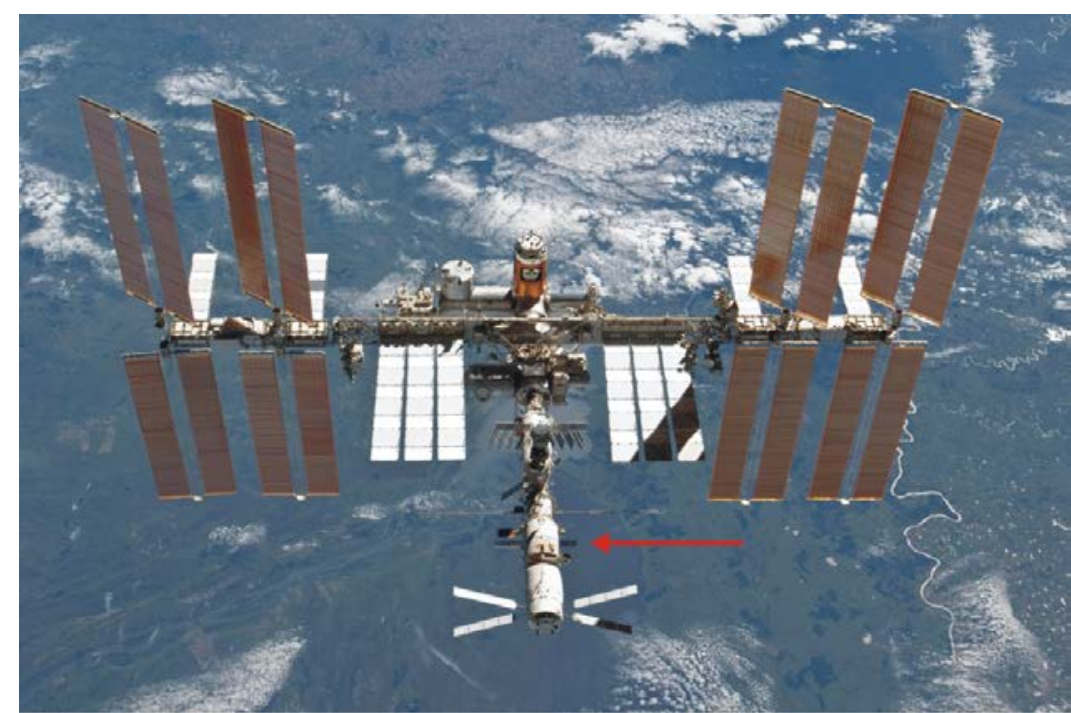

B

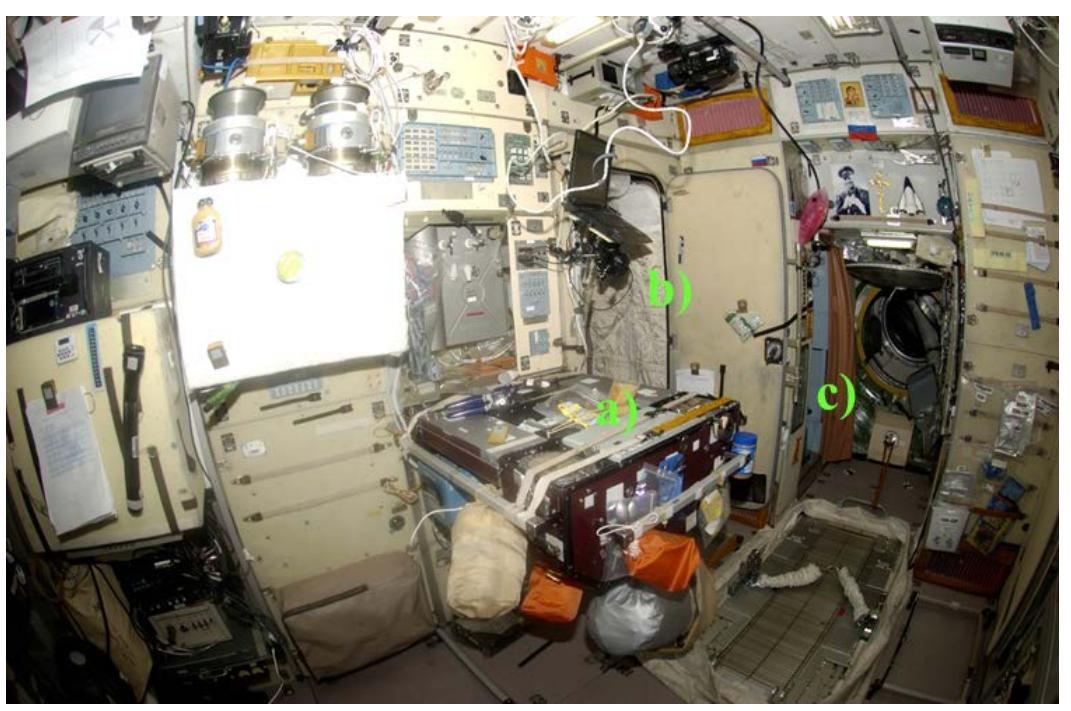

C

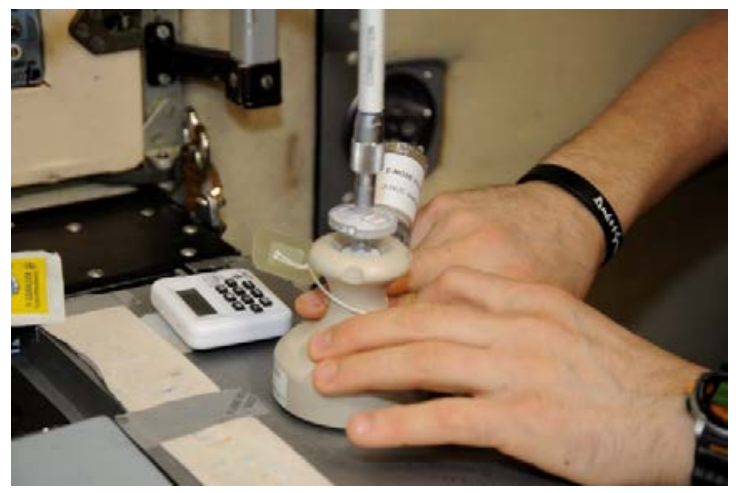

D

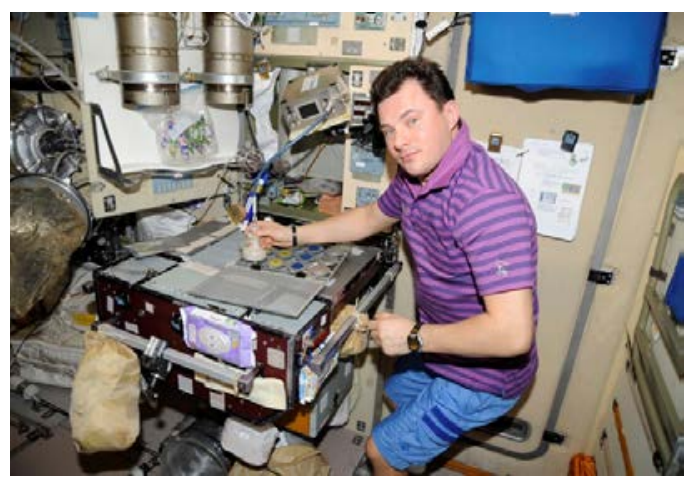

Figure 5. (A) Photograph of the International Space Station (ISS). The Russian segment with the Zvezda Service Module in which the measurements were performed is labeled with a red arrow (photograph from: http://www.nasa.gov). (B) Illustration of the three measurement locations at the Zvezda Service Module: a) working table, b) sleeping cabin, and c) toilet lid. (C) Measurement of working table with the E-Nose. The astronaut presses the air sampler against the working table. (D) Negative control measurements in space. The cosmonaut measures the sterile Target Book. 
was observed that eight out of nine measurements showed valid results exhibiting gas response patterns for the three locations described above and for the negative control taken on the Target Book. Only the measurements from location $b$ in the last test series did not produce any useful results because the sensor signals arising from the MVOCs were too weak to be safely distinguished from the sensor background noise. These small sensor signals, therefore, were discarded and excluded from any further evaluation.

\section{Data Processing and Results from Raw Data of the Memory Card}

The remaining eight measurements were compared to an odor database that had been developed by teaching the E-Nose with smell patterns originating from four specifically selected reference organisms in a laboratory on Earth. All four organisms used for the teaching campaign were previously found at the ISS and were typically part of its microbiological ecosystem. This included two species of fungi (A. versicolor and $P$. expansum) and two bacterial species ( $B$. subtilis and $S$. warneri), which were used to establish the odor database of the E-Nose (publication in preparation). After comparing the signals from the odor database with those obtained in space, all eight signals (pink rhombs Figure 6A) were located in nearly the same region of the PC1 vs. PC2 score plots. Compared to the negative control (Target Book) measurements in space a clear separation could be recognized. Further, the PC1/2 score plot shows that the measurements inside the ISS were positioned close to the cluster of $B$. subtilis (green squares), which is located in the top right corner of Figure 6A. In contrast, the common cluster arising from fungi ( $P$. expansum, blue triangles and $A$. versicolor, turquoise triangles) were far from the ISS-signals, which were located in the bottom right quadrant of the $\mathrm{PC} 1 / 2$ score plot. The odor from $S$. warneri (red rhombs) did not coincide with the space data because the cluster is positioned between $B$. subtilis and the fungi in the top right quadrant in the $\mathrm{PC} 1 / 2$ score plot. Both the negative controls from the Target Book taken in space (pink rhombs) and the negative controls from the teaching campaign of the E-Nose on Earth (gray spheres; culture medium without microorganisms) coincided very closely, being located in the left-hand center of the $\mathrm{PC} 1 / 2$ sore plot (Figure 6A).

Considering the PC1/3 score plot (Figure 6B), it became evident that the ISS data were located in a direction perpendicular to the $\mathrm{PC} 1 / 2$ score plane, which contains more or less all of the data from our initial training set. Only the space measurement of location $\mathrm{c}$ during the second measurement campaign (2-c) stood out from the remaining seven E-Nose measurements. A similar situation was also observed in the PC2/3 score plots. The taught species and the negative controls built clusters of their own, distinct from those data obtained onboard the ISS (Figure 6C). In the PC3/4 score plots, the ISS data clearly stood out from those data obtained during the training campaign. Further, in the PC $3 / 4$ score plots, the space data exhibited the highest variance, which allowed the individual space measurements to be easily distinguished (Figure 6D). In summary, the information obtained from the PCA of the space data showed that their clusters are dissimilar from those of the training set and distinguishable from those of the negative control measurements.

\section{Determination of CFU from Surface Samples and Identification of Selected Pure Cultures}

The swab containers brought back to Earth were opened under sterile conditions and microbial concentrations were determined from all three swabs (Q1-Q3) on six different culture plates as described in the materials and methods section. The greatest number of CFUs was found on Q2 (sleeping cabin), amounting to $1.91 \mathrm{E}+07$, followed by Q3 (toilet lid) with $6.50 \mathrm{E}+04 \mathrm{CFU}$, and $1.63 \mathrm{E}+02 \mathrm{CFU}$ on Q1 (working table). Depending on the culture plates, the most CFUs grew on TSA, followed by YEA, SGA, and R2A. No colonies were found on MacConkey agar or MSA from any of the three cotton swabs, as shown in Table 1. After determination of the CFUs from the swabs, 25 colonies were selected from the culture plates to obtain 25 pure cultures. Care was taken to obtain pure cultures across all plates and to select different colonies on the basis of their colony morphology. The aim was to capture as many different colonies as possible to obtain a significant picture of the microbiological environment of the three swabbed locations a-c. In 
Reidt et al. -- Electric Nose Detects Microorganisms on ISS

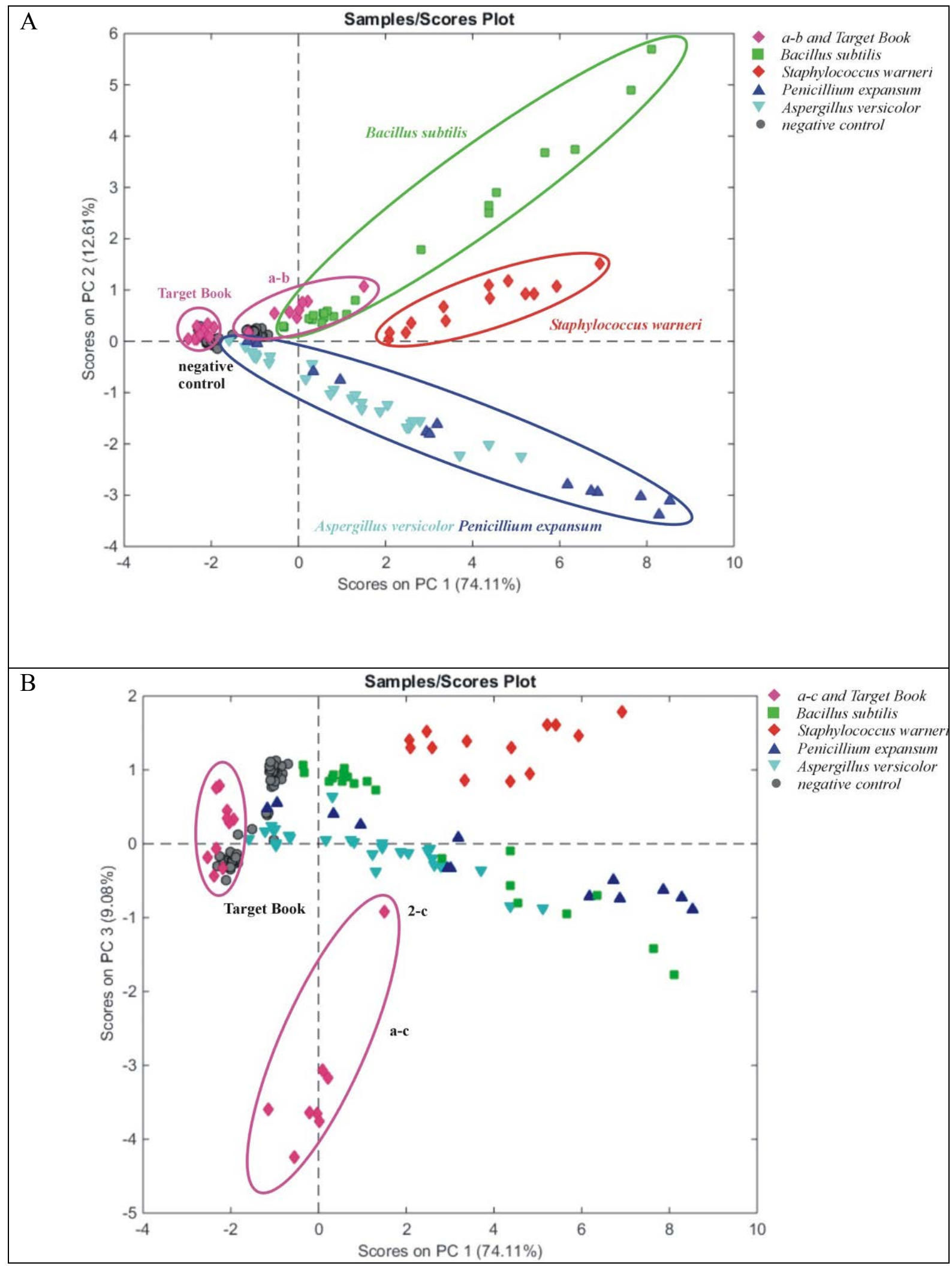


Reidt et al. -- Electric Nose Detects Microorganisms on ISS

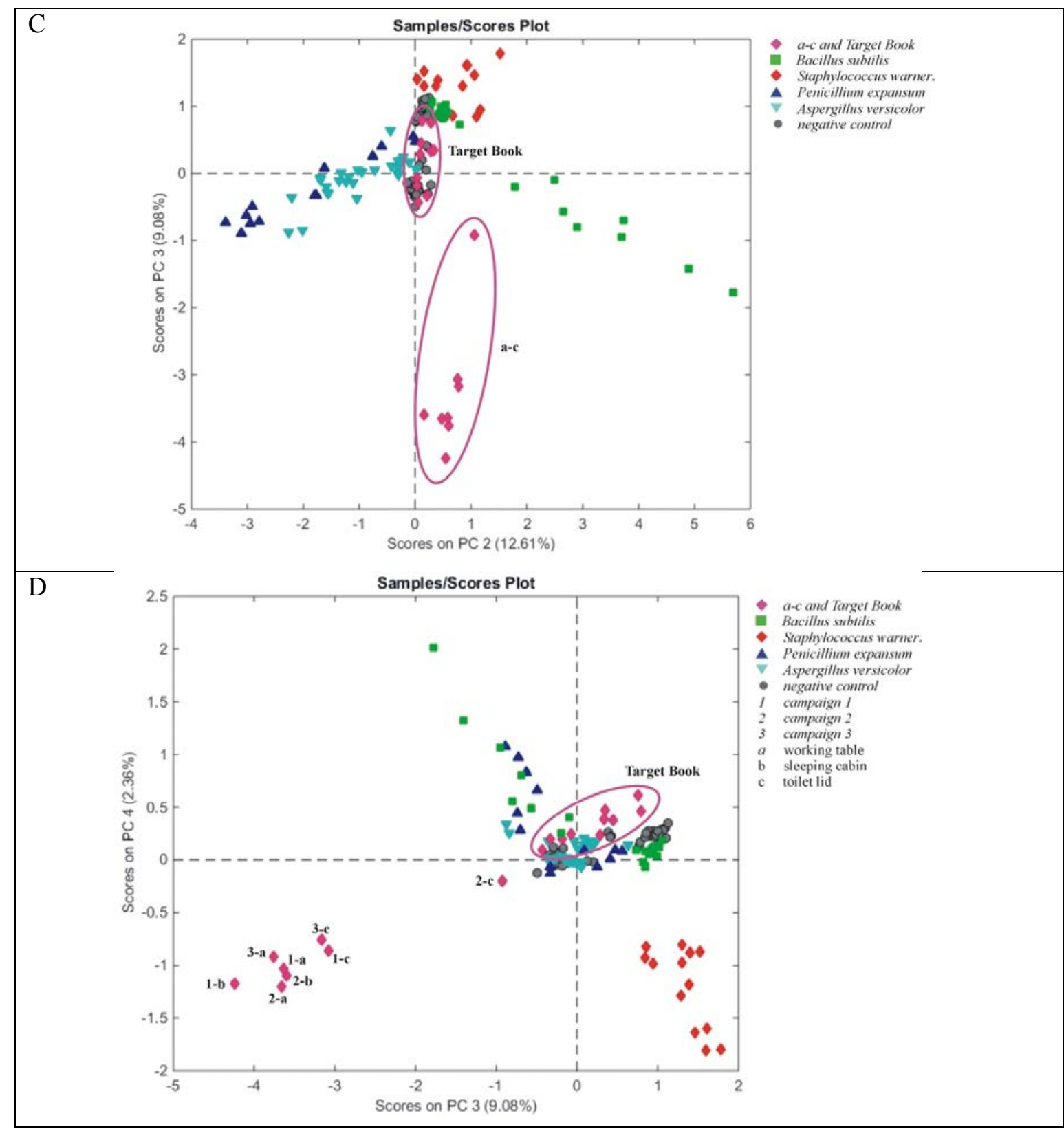

Figure 6. (A) Comparison of the measurements from the ISS (measurement locations and Target Book in pink rhombs) with the four teaching organisms Bacillus subtilis (green squares), Staphylococcus warneri (red rhombs), Penicillium expansum (blue triangle), and Aspergillus versicolor (turquoise triangles). In score plot PC1/2, the space measurements were located close to the cluster of $B$. subtilis and the negative controls (gray spheres). (6B) Representation of the measurements at ISS (a-c) in score plot PC1/3 related to all four teaching organisms (B. subtilis, $S$. warneri, $P$. expansum, and $A$. versicolor). The E-Nose measurements at the ISS were located distal from all teaching species. Only the measurement at position c (toilet seat) in test series 2 (2-c) is located outside of the remaining seven E-Nose measurements (a-c). (C) In score plot PC2/3, results from space measurements were presented versus the teaching organisms. Measurements performed at the ISS build a cluster separate from all other measurements. (D) Detailed description of the E-Nose measurements obtained at Zvezda Service Module illustrated in score plot PC3/4. From left to right; 1-b: campaign 1, location b (sleeping cabin); 3-a: campaign 3, location a (working table); 2-a: campaign 2, location a (working table); 1-a: campaign 1, location a (working table); 2-b: campaign 2, location b (sleeping cabin); 3-c: campaign 3, location c (toilet lid); 1-c: campaign 1, location c (toilet lid); 2-c: campaign 2, location c (toilet lid). 
Reidt et al. -- Electric Nose Detects Microorganisms on ISS

Table 1. Determination of colony forming units (CFU) from the washout of swabs.

\begin{tabular}{|c|c|c|c|}
\hline Culture media & $\begin{array}{c}\text { Q1 (working table), } \\
\text { CFU/mL }\end{array}$ & $\begin{array}{c}\text { Q2 (sleeping cabin), } \\
\text { CFU/mL }\end{array}$ & $\begin{array}{c}\text { Q3 (toilet lid), } \\
\text { CFU/mL }\end{array}$ \\
\hline MacConkey Agar & 0 & 0 & 0 \\
\hline Mannitol Salt Agar & 0 & 0 & 0 \\
\hline R2A Agar & 140 & $3.9 \mathrm{E}+04$ & 0 \\
\hline $\begin{array}{c}\text { Sabouraud 4\% Glucose } \\
\text { Agar }\end{array}$ & 1 & $4.0 \mathrm{E}+04$ & 0 \\
\hline Tryptic Soy Agar & 2 & $1.9 \mathrm{E}+07$ & $3.7 \mathrm{E}+04$ \\
\hline Yeast Extract Agar & 20 & $2.5 \mathrm{E}+04$ & $2.8 \mathrm{E}+04$ \\
\hline$\sum:$ CFU/mL & $1.63 \mathrm{E}+02$ & $1.91 \mathrm{E}+07$ & $6.50 \mathrm{E}+04$ \\
\hline
\end{tabular}

the next step, genomic DNA was isolated from each pure culture by using nexttec ${ }^{\mathrm{TM}}$ cleanColumns. For subsequent BLAST analysis, PCR was used to amplify a 723-bp fragment of the 16S rRNA gene from bacteria and a 555-bp region of the $18 \mathrm{~S}$ rRNA gene from fungi. The sequences of all PCR products were analyzed by performing a standard nucleotide BLAST. From 25 initial PCR products originating from pure cultures, 14 total different bacterial (12) and fungal (2) species were identified from the swabs. From fungal cultures, the strain P. expansum and the strain Fusarium oxysporum were identified. In the case of the prokaryotes, Gram-positive bacteria dominated with 9 species in which the genera of Staphylococcus (4 species) and Bacillus (3 species) were abundant. As shown in Table 2, the genus Staphylococcus was found in all three locations (a-c), whereas Bacillus could be detected only in the sleeping cabin and toilet lid. The largest quantity of bacteria $\left(1.9 \mathrm{E}^{+07}\right.$ $\mathrm{CFU} / \mathrm{mL}$ ), which was found at location $b$ and grew on TSA, belongs to the Gram-negative bacterial species Pseudomonas geniculate.

Table 2. Genetic identification of microorganisms in 25 pure cultures from selected colonies by BLAST analysis.

\begin{tabular}{|c|c|c|}
\hline Q1 (working table) & Q2 (sleeping cabin) & Q3 (toilet lid) \\
\hline Penicillium expansum ${ }^{\mathrm{f}}$ & Agrobacterium tumefaciens ${ }^{\mathrm{b},-}$ & Bacillus subtilis ${ }^{\mathrm{b},+}$ \\
\hline Staphylococcus epidermidis ${ }^{\mathrm{b},+}$ & Bacillus agaradhaerens ${ }^{\mathrm{b},+}$ & Staphylococcus warneri ${ }^{\mathrm{b},+}$ \\
\hline \multirow[t]{6}{*}{ Streptococcus salivarius ${ }^{\mathrm{b},+}$} & Bacillus atrophaeus ${ }^{\mathrm{b},+}$ & Staphylococcus epidermidis ${ }^{\mathrm{b},+}$ \\
\hline & Fusarium oxysporum ${ }^{\mathrm{f}}$ & \\
\hline & Micrococcus luteus ${ }^{\mathrm{b},+}$ & \\
\hline & Pseudomonas geniculata ${ }^{\mathrm{b},-}$ & \\
\hline & Staphylococcus hominis ${ }^{\mathrm{b},+}$ & \\
\hline & Stenotrophomonas maltophilia ${ }^{\mathrm{b},-}$ & \\
\hline
\end{tabular}

b: bacteria, f: fungi, +: Gram positive, -: Gram negative 
Reidt et al. -- Electric Nose Detects Microorganisms on ISS

\section{Identification of Rhodotorula mucilaginosa and Rhodotorula glutinis by E-Nose}

Comparing the genetically identified species with the odor database formed by the training set of the E-Nose, three of the four microorganisms from the odor database were clearly rediscovered. These organisms were the two bacteria species $B$. subtilis and $S$. warneri and the fungal strain $P$. expansum. However, it seems that the quantity of microorganisms was not high enough to detect their bacterial smells with the E-Nose. On the other hand, all locations showed measurable quantities of MVOCs, which did not coincide with those of the four organisms of the training set or those of the negative controls. This raises the question: Which species has generated the signals measured by the E-Nose? Trying to clarify this question, the following investigations were made: First, the bacterial strain $P$. geniculate was tested for its smell in an additional teaching campaign with the E-Nose because $P$. geniculate is Gramnegative and no Gram-negative bacteria had yet been tested. Furthermore, P. geniculate was the most prevalent in Q2 washouts (sleeping cabin), with $1.9 \mathrm{E}+07$ CFUs $/ \mathrm{mL}$. Both arguments hypothesized that $P$. geniculate is probably the sought-after species that generated the unknown odor. However, after correlation trials, it appeared that $P$. geniculate (green rhombs) builds a cluster of its own in the opposite quadrant of the PC1/2 score plot, in contrast to the signals obtained onboard the ISS (Figure 7A). This suggests that the unknown organism is neither a bacterial strain nor a typical mold fungus. After further consideration and literature research, a yeast was suspected as the sought-after organism (Novikova et al., 2006; Novikova et al., 2009). It was found that the baker's yeast Saccharomyces cerevisiae generates a cluster (orange squares) in the $\mathrm{PC} 1 / 2$ score plot that spreads into the bottom right direction relative to the ISS-signals (Figure 7B). In the literature, the genus Rhodotorula is described to be present in the environment of the ISS (Novikova et al., 2006) (Novikova et al., 2009). Based on this knowledge, the smell of yeast strain Rhodotorula mucilaginosa was tested with the E-Nose and it was found that the unknown signals from ISS measurements coincided in a common cluster in the PC $1 / 2$ score plot (Figure 7C). Furthermore, as seen in the
PC3/4 score plot, the new signals from $R$. mucilaginosa almost completely coincided with those signals measured onboard the ISS (Figure 7D). Based on these results, it was concluded that the unknown signals from the three locations in the Zvezda Service Module at ISS were actually produced by the yeast genus Rhodotorula.

\section{Identification of Rhodotorula spp. by PCR and rRNA Gene Sequencing from Washout}

As described in the materials and methods section, the swabs (Q-tips) from space were washed out in $1 \mathrm{~mL}$ sterile $\mathrm{NaCl} 0.85 \%$ (w/v) and stored at $-87^{\circ} \mathrm{C}$ after determination of the CFUs. To identify the yeast Rhodotorula, the frozen washouts were cultured on yeast agar plates, but after incubation times of more than 14 days at $25^{\circ} \mathrm{C}$ no yeast colonies could be observed. After this negative result, an attempt was made to detect Rhodotorula by molecular genetic methods. With the universal fungal primers NS1/NS2, rRNA gene fragments were amplified from all three washouts of the surface samples Q1-Q3 indicating that a yeast or other fungus is present. Electrophoretic analysis revealed PCR fragments of the correct size (Figure 8A). Sample Q2 especially generated a high amount of fungal ribosomal 18S RNA. From samples Q1 and Q3, a lower amount was amplified. The negative control and not template control (NTC) resulted in no signal at all. Subsequent sequence data analysis of the purified PCR products of surface samples Q1 and Q3 indicated an uncultured fungus clone for both strands. For surface sample Q2, the comparison by BLAST of sequences from both strands indicated the yeast species Rhodotorula; the forward sequence even corresponds in a specific manner to a Rhodotorula mucilaginosa sequence.

Real-time PCR of Rhodotorula glutinis and Rhodotorula mucilaginosa from Washout of Surface Sample Q2

Further analysis of $R$. mucilaginosa by realtime PCR with the DNA from the washout of the surface samples revealed a strong signal from Q2. As a positive control, DNA from a pure culture of $R$. mucilaginosa (Deutsche Sammlung von Mikroorganismen und Zellkulturen; DSMZ strain 70403) was isolated according to the nexttec ${ }^{\mathrm{TM}}$ protocol described 


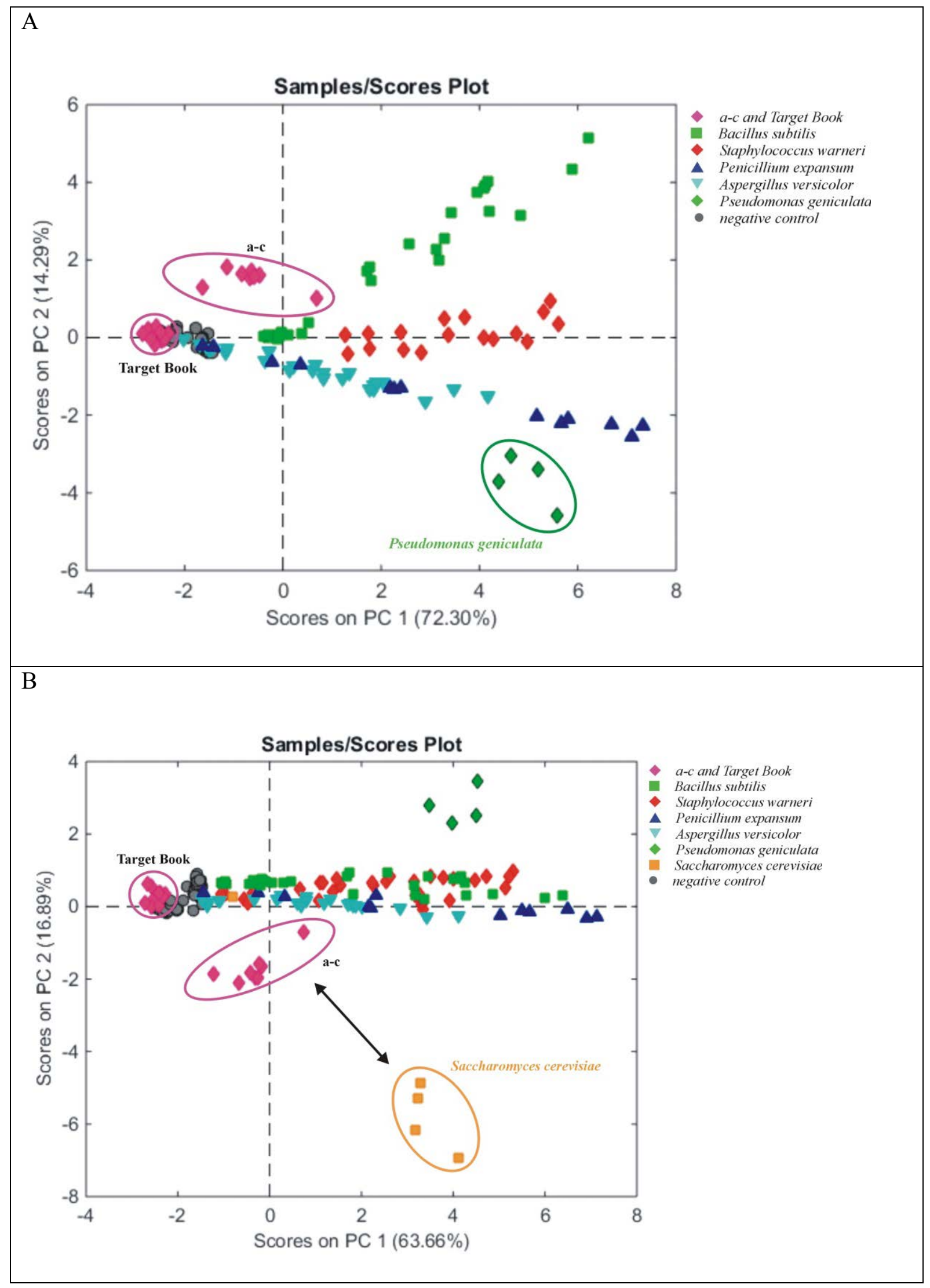


Reidt et al. -- Electric Nose Detects Microorganisms on ISS

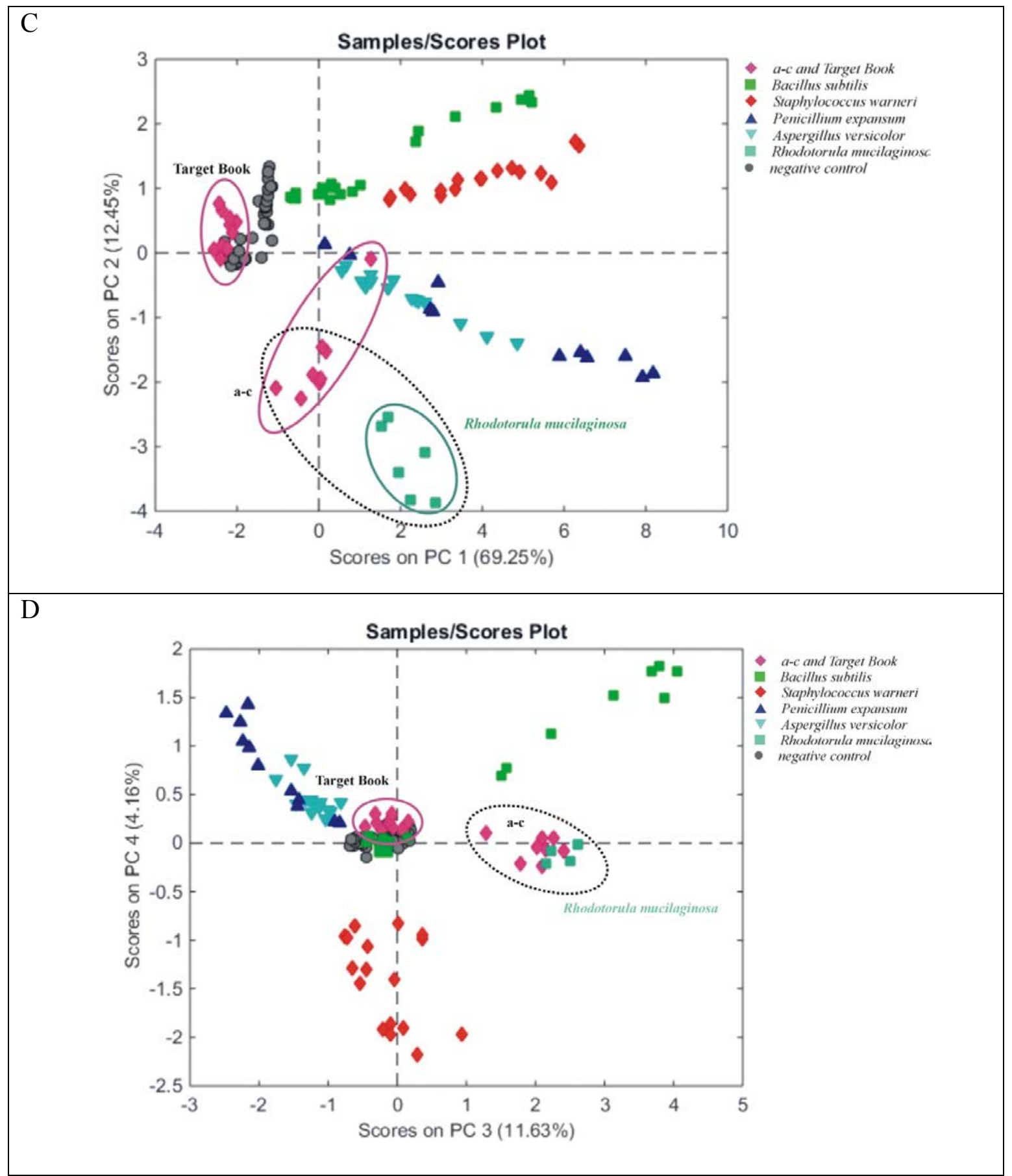

Figure 7. (A) Additional teaching of the E-Nose by Pseudomonas geniculate and comparison with the measurements from ISS (a-c). In score plot PC1/2 P. geniculate (green rhombs) builds a distinct cluster at the opposite quadrant of the space measurements. (B) Comparison of measurements in space and the odor determined from Saccharomyces cerevisiae (orange squares) illustrated in the score plot PC1/2. Odor signals spread out in the right direction. (C) Teaching of the E-Nose by the yeast strain Rhodotorula mucilaginosa versus measurements performed at the ISS (a-c). Both signals coincide in one common cluster in the score plot PC1/2. (D) Score plot PC3/4 of the signals from $R$. mucilaginosa and the measurements in space. The signals coincide. 


\section{Reidt et al. -- Electric Nose Detects Microorganisms on ISS}

above. To prove that there was no unspecific reaction of the real-time PCR with any other Rhodotorula species, DNA was purified and tested in the same way from a pure culture of Rhodotorula glutinis (DSMZ strain 10134). As a negative control, the DNA isolation procedures were performed with pure water. To check the qPCR assay for contamination, an NTC was used with $5 \mu \mathrm{L}$ pure water instead of a sample. The analysis showed that $R$. mucilaginosa can be specifically detected in surface sample Q2. The other samples produced a negative result. The positive control also revealed a strong signal. Only a weak cross-reactivity with $R$. glutinis was observed (Figure 8B).

\section{DISCUSSION}

With the successful operation of the E-Nose onboard the ISS, a clear step has been made towards bio-detection systems that can be operated under microgravity conditions inside spacecraft, with only electricity required as a consumable. The experiments performed by the cosmonaut Roman Romanenko have moreover shown that E-Nose systems are easy to handle and allow data on microbial contamination to be obtained in almost real-time without earthbound laboratories. As such water-independent detection systems do provide a fully local analysis of the microbial contamination inside a spaceship, the developed E-Nose systems are not only useful for operation inside the ISS but also hold promise for much longer space missions, such as flights to Mars.

In this work, we report for the first time the use of an electronic nose for the detection and identification of microorganisms onboard the ISS. This E-Nose, which contains ten different MOX gas sensors, was trained by making use of the available knowledge about microbial contamination onboard the ISS. Using standard methods of microbiological analysis, it was found that this microbial contamination includes no less than 76 different species detected on 1075 samples taken from surfaces and the air inside the ISS. According to that study, the rate of occurrence of the most dominant bacterial species in surface samples were Staphylococcus spp. with $85.2 \%$ followed by Bacillus spp. with $32.3 \%$ and the most dominant fungi were Aspergillus spp. with $19.6 \%$ and Penicillium spp. with $10.6 \%$ (Novikova et al., 2009). Similar rates of occurrence were also detected in our work because Staphylococcus spp., Bacillus spp., and Penicillium spp. were also identified in the swabs. Considering the fact that 76 species of bacteria and fungi were well described in the environment of the ISS (Novikova et al., 2009) and that the odor database contains only 4 different species, this means that only the species from this small subset can be positively identified, leaving the major part of the microbial contamination unidentified.

The key finding of our investigation was that the odors detected by the E-Nose were dominated by signals deriving from the yeast $R$. mucilaginosa. This yeast was detected by the ENose in all investigated locations, but the standard methods of analysis detected a variety of other species with higher probability of occurrence and with location-specific rates of detection. The detection of $R$. mucilaginosa, on the other hand, is consistent with earlier studies of the surface contamination inside the ISS, which have identified related Rhodotorula spp. and Saccharomyces spp. (Alekhova et al., 2005; Novikova et al., 2009; Satoh et al., 2011). Furthermore, in the Russian segment of the ISS, the yeast Rhodotorula rubra has been isolated (Novikova et al., 2006). Representatives of the genus Rhodotorula were also found in other extreme environments, e.g., in lakes with a naturally acidic environment, in hypersaline diversity habitats, in Antarctic sea water, and even within radioactive waste (Butinar et al., 2005; Russo et al., 2008; Laich et al., 2013; Li et al., 2015). On the basis of these observations, it is not surprising that Rhodotorula spp. was also identified onboard the ISS.

With regard to E-Nose detection, the relevant question is: Why are yeasts so well detected by the E-Nose? The most likely reason is that yeasts produce MVOCs that react very sensitively with MOX surfaces. Research on the species $S$. cerevisiae using the MVOC database from the University of Rostock and the Charité in Berlin, Germany (Lemfack et al., 2014) indicated that 26 kinds of MVOCs might be emitted by this yeast as listed in Table 3. Among these, the most abundant chemical compounds were alcohols, followed by 
Reidt et al. -- Electric Nose Detects Microorganisms on ISS

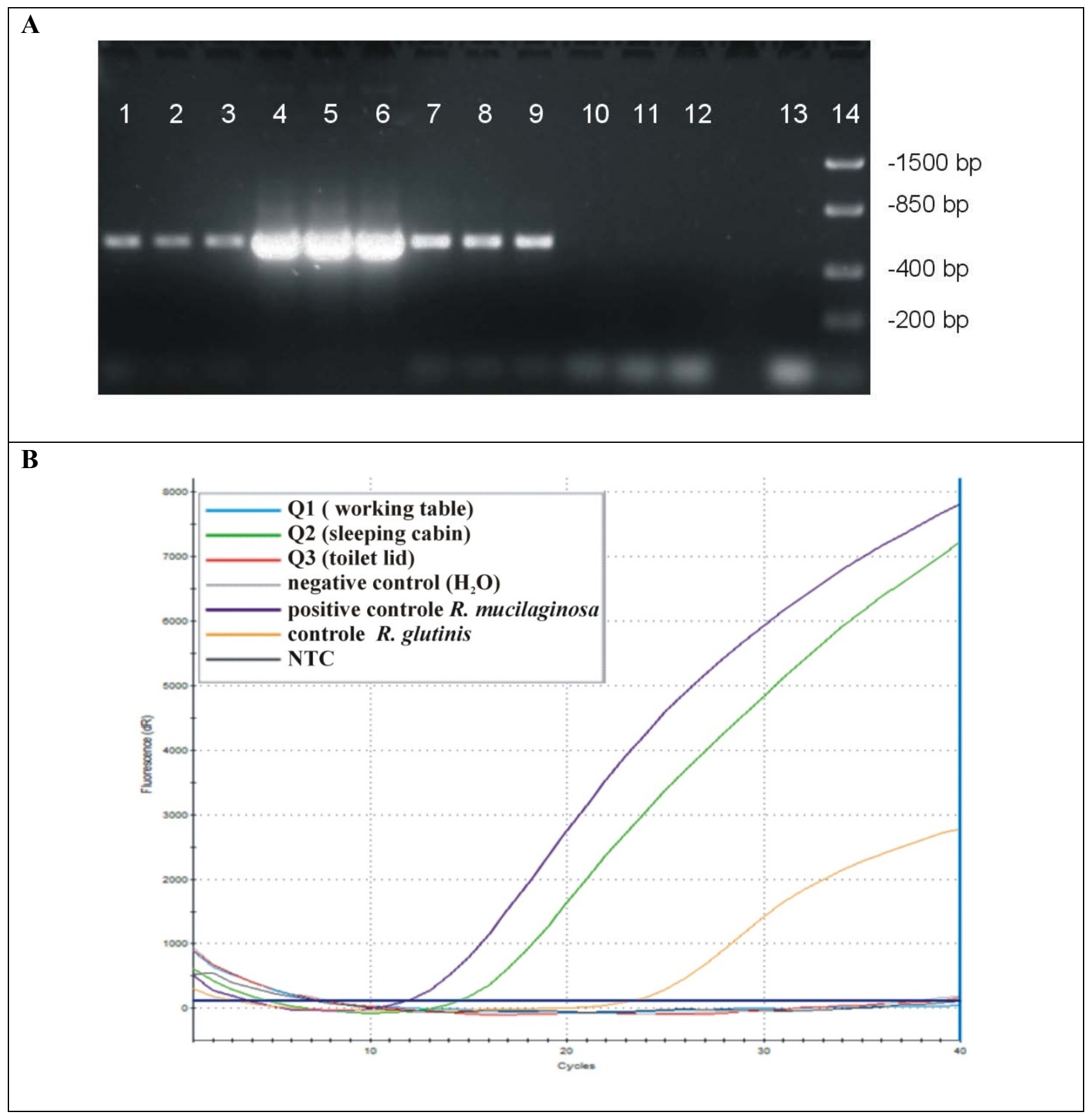

Figure 8. (A) Electrophoretic analysis of PCR fragments generated with the primer pair NS1/ NS2 from DNA of the surface samples Q1 (working table), Lanes 1-3; Q2 (sleeping cabin), Lanes 4-6; and Q3 (toilet lid), Lanes 7-9. As a negative control, $0.85 \%(\mathrm{w} / \mathrm{v}) \mathrm{NaCl}$ solution in place of a sample was processed to show that there is no unspecific yeast DNA background in any of the reagents used (Lanes 10-12). As no template control (NTC), $5 \mu \mathrm{L}$ of pure water was added to the PCR assay (Lane 13). The size marker was applied in Lane 14 and labeled on the left-hand side. (B) Real-time PCR specifically analyzing the DNA from Rhodotorula mucilaginosa that was isolated from the three surface samples Q1 (working table), Q2 (sleeping cabin), and Q3 (toilet lid). For sample Q2, a strong signal could be detected. No presence of $R$. mucilaginosa DNA was seen in Q1 and Q3. As a negative control, the whole method was performed with pure water instead of a sample to assure that there is no unspecific $R$. mucilaginosa DNA in any of the reagents used. For the positive control, DNA from a pure culture of $R$. mucilaginosa was isolated and added to the qPCR assay. To check whether there is any unspecific reaction with other Rhodotorula species, DNA from a pure culture of $R$. glutinis was used. For the NTC, $5 \mu \mathrm{L}$ of pure water were analyzed with the qPCR assay. 
Reidt et al. -- Electric Nose Detects Microorganisms on ISS

Table 3. Theoretical prediction of the MVOCs from Saccharomyces cerevisiae compared to sensor compound sensitivity of the E-Nose.

\begin{tabular}{|c|c|c|}
\hline \multicolumn{2}{|c|}{ Saccharomyces cerevisiae } & E-Nose \\
\hline MVOC & $\begin{array}{l}\text { Chem. } \\
\text { classification }\end{array}$ & $\begin{array}{l}\text { No. of sensors and compounds } \\
\text { sensitivity }\end{array}$ \\
\hline 1-Propanol & Alcohol & Sensor 1: Aromatic compound, Alkane \\
\hline 2-Ethyl-1-hexanol & Alcohol & $\begin{array}{l}\text { Sensor 2: Nitrogen oxides, Alcohols, } \\
\text { Aromatic compounds }\end{array}$ \\
\hline 2-Methyl-1-propanol & Alcohol & Sensor 3: Aromatic compound, Alkane \\
\hline 2-Propanol & Alcohol & Sensor 4: Hydrogen \\
\hline Ethanol & Alcohol & Sensor 5: Aromatic compounds, Alkane \\
\hline Phenethyl Alcohol & Alcohol & Sensor 6: Methane, Alcohol \\
\hline 2-(Ethenyloxy)-ethanol & $\begin{array}{l}\text { Alcohol, Ether, } \\
\text { Alkene }\end{array}$ & $\begin{array}{l}\text { Sensor 7: Inorganic sulfur compounds, } \\
\text { Terpenes, Sulfur-containing organic } \\
\text { compounds, Aromatic compound }\end{array}$ \\
\hline $\begin{array}{l}\text { 1,2-Benzenedicarboxylic } \\
\text { Acid }\end{array}$ & Acid & Sensor 8: Alcohol, Aromatic compound \\
\hline 2-Methyl Propanoic Acid & Acid & $\begin{array}{l}\text { Sensor 9: Aromatic compounds and } \\
\text { inorganic sulfur compounds as } \mathrm{H}_{2} \mathrm{~S}\end{array}$ \\
\hline 2-Methylbutanoate & Acid & $\begin{array}{l}\text { Sensor 10: Methane and aliphatic organic } \\
\text { compounds }\end{array}$ \\
\hline 3-Methylbutanoic Acid & Acid & \\
\hline Acetic Acid & Acid & \\
\hline 2-Butanone & Ketone & \\
\hline 2-Pentanone & Ketone & \\
\hline 2-Propanone & Ketone & \\
\hline $\begin{array}{l}\text { 1,9- } \\
\text { Dimethylspiro(4,5)decane }\end{array}$ & Alkane & \\
\hline Undecane & Alkane & \\
\hline Alpha-limonene & \begin{tabular}{|l|} 
Alkene, \\
Terpene
\end{tabular} & \\
\hline 3-Methyl butanal & Aldehyde & \\
\hline Acetaldehyde & Aldehyde & \\
\hline Acetic Acid Ethenyl Ester & Ester & \\
\hline Ethyl Acetate & Ester & \\
\hline Pyrazine & Pyrazine & \\
\hline 2,5-Dimethylpyrazine & Pyrazine & \\
\hline Dimethyl Disulfide & Sulfide & \\
\hline Ortho-Dimethylbenzene & Benzenoid & \\
\hline
\end{tabular}




\section{Reidt et al. -- Electric Nose Detects Microorganisms on ISS}

acids, ketones, and alkanes. Comparing the relative sensitivities with which chemical compounds can be detected by the MOX sensors in our array, alcohols and alkanes were among those that could be detected at single-ppm concentrations. Two more molecules that were found to react very well are alpha-limonene and dimethyl disulfide. These sulfur-containing MVOCs are also very dominant because of their odorous smell. Dimethyl disulfide, in particular, is known to be a very strong scent and a metabolic product of Phallus impudicus, an extremely unpleasant-smelling fungus (Pudil et al., 2014). To summarize, alcohols, alkanes, and sulfurcontaining organic compounds are very intensive odors that react very sensitively with MOX sensors and are therefore likely to overwhelm less reactive molecules of other microorganisms. In view of this situation, it may well happen that low concentrations of very reactive MVOCs will dominate much higher concentrations of less reactive MVOCs; for instance, methane, which causes only a small sensor reaction, could easily be overwhelmed.

The presently reached state of the art is satisfactory if the dominating yeasts coincide, for well-understood biological reasons, with the rest of the microbiological diversity. In this case, ENose sensor signals can be taken as indicators for necessary countermeasures. Working towards higher levels of discrimination, the presently small training set needs to be massively expanded. Such measures, however, will only be successful if the discrimination capabilities of the presently used MOX sensor array can be extended. Within such an ameliorated sensor array, a fraction of the sensors need to be partially blinded in the sense that they no longer respond to the most highly reactive MVOCS, leaving sensitivity to those that are not readily reactive on MOX sensor surfaces, such as methane. A possible measure of achieving this is covering a fraction of the MOX sensors with heated, porous catalytic filters (Fleischer et al., 2000).

The microbial contamination within the Zvezda Service Module of the Russian segment of the ISS has been investigated with the help of an electronic nose containing ten different MOX gas sensors. To arrive at a comprehensive assessment of the capabilities of MOX-based electronic noses, all investigated surfaces were wiped with swabs and the swabs were analyzed with a range of standard microbiological methods. Comparison of the E-Nose and the standard microbiological results has shown that E-Noses are sensitive mainly to yeasts, which are a minority of the microbiological contamination according to normal microbiological assessments. The likely reason for the E-Nose dominance of yeasts is that these excrete MVOCs that are highly reactive on MOX surfaces. Likely MVOC candidates for this effect are alcohols and sulfur-containing gaseous compounds. Further development of our E-Nose system will involve a massive expansion of the microbial training set and changes in the MOX sensor array to allow for the detection both of high- and low-reactivity MVOCs at the same time.

\section{ACKNOWLEDGEMENTS}

This work was supported by funding from the E-Nose project from Deutsches Zentrum für Luftund Raumfahrt (DLR) in Bonn, Germany. We gratefully acknowledge the Cosmonaut Roman Yurievich Romanenko, who performed the experiments onboard the ISS. Also, we acknowledge the Russian Federal Space Agency Roscosmos and the S.P. Korolev Rocket and Space Corporation Energia. In addition, we would like to thank NASA for use of the photograph from the ISS.

\section{REFERENCES}

Alekhova TA, Aleksandrova AA, Novozhilova T, Lysak LV, Zagustina NA, Bezborodov AM (2005) Monitoring of microbial degraders in manned space stations. Prikladnaia Biokhimiia Mikrobiologia 41: 435-443

Benson DA, Boguski MS, Lipman DJ, Ostell J, Ouellette BF, Rapp BA, Wheeler DL (1999) GenBank. Nucleic Acids Research 27: 1217

Bruins M, Bo, A, Petit PL, Eadie K, Rog A, Bos $\mathrm{R}$, van Ramshorst $\mathrm{GH}$, van Belkum A (2009) Device-independent, real-time identification of bacterial pathogens with a metal oxide-based olfactory sensor. European Journal of Clinical Microbiology \& Infectious Diseases 28: 775-780 
Butinar L, Santos S, Spencer-Martins I, Oren A, Gunde-Cimerman N (2005) Yeast diversity in hypersaline habitats. FEMS Microbiology Letters 244: 229-234

Diaz C, Molina AM, Nahring J, Fischer R (2013) Characterization and dynamic behavior of wild yeast during spontaneous wine fermentation in steel tanks and amphorae. Biomed Research International 2013: 540465

Dutta R, Hines EL, Gardner JW, Boilot P (2002) Bacteria classification using Cyranose 320 electronic nose. Biomedical Engineering OnLine 1: 4

Fleischer M, Kornely S, Weh T, Frank J, Meixner H (2000) Selective gas detection with hightemperature operated metal oxides using catalytic filters. Sensors and Actuators B: Chemical 69: 205-210

Klintworth R, Reher HJ, Viktorov AN, Bohle D (1999) Biological induced corrosion of materials II: new test methods and experiences from MIR station. Acta Astronautica 44: 569-578

Korpi A, Pasanen AL, Pasanen P (1998) Volatile compounds originating from mixed microbial cultures on building materials under various humidity conditions. Applied and Environmental Microbiology 64: 29142919

Kuske CR, Banton KL, Adorada DL, Stark PC, Hill KK, Jackson PJ (1998) Small-scale DNA sample preparation method for field PCR detection of microbial cells and spores in soil. Applied and Environmental Microbiology 64: 2463-2472

Laich F, Vaca I, Chavez R (2013) Rhodotorula portillonensis sp. nov., a basidiomycetous yeast isolated from Antarctic shallow-water marine sediment. International Journal of Systematic and Evolutionary Microbiology 63: 3884-3891

Lemfack MC, Nickel J, Dunkel M, Preissner R, Piechulla B (2014) mVOC: a database of microbial volatiles. Nucleic Acids Research 42: D744-748

Li CC, Chung HP, Wen HW, Chang CT, Wang YT, Chou FI (2015) The radiation resistance and cobalt biosorption activity of yeast strains isolated from the Lanyu lowlevel radioactive waste repository in
Taiwan. Journal of Environmental Radioactivity 146: 80-87

Novikova ND, De Boever P, Poddubko S, Deshevaya E, Polikarpov N, Rakova N, Coninx I, Mergeay M (2006) Survey of environmental biocontamination on board the International Space Station. Research in Microbiology 157: 5-12

Novikova ND, Pierson DL, Poddubko SV, Deshevaya YA, Ott CM, Castro VA, Bruce RJ (2009) Microbiology of the International Space Station. In U.S. and Russian Cooperation in Space Biology and Medicine, A Nicogossian, $\mathrm{O}$ Gazenko, A Grigoriev (eds), pp. 263-278. Washington D.C.: American Institute of Aeronautics and Astronautics

Pierson DL (2001) Microbial contamination of spacecraft. Gravitational and Space Biology Bulletin 14: 1-6

Prokhorov KS (2009) Life Support Systems Safety. In Safety Design for Space Systems, GE Musgrave, ASM Larsen, T Sgobba (eds), pp. 185-224. Burlington, MA: Butterworth-Heinemann

Pudil F, Uvira R, Janda V (2014) Compounds in stinkhorn (Phallus impudicus L. Ex. Pers.) at different stages of growth. European Scientific Journal 10: 163-171

Reidt U, Plobner L, Lugmayr V, Treutlein U, Kharin S, Smirnov Y, Novikova ND, Lenic J, Fetter V, Hummel T (2014) Study of initial colonization by environmental microorganisms in the Russian segment of the International Space Station (ISS). Gravitational Space Research 2: 46-57

Russo G, Libkind D, Sampaio JP, van Broock MR (2008) Yeast diversity in the acidic Rio Agrio-Lake Caviahue volcanic environment (Patagonia, Argentina). FEMS Microbiology Ecology 65: 415-424

Ryan MA, Manatt MK, Gluck SE, Shevade AV, Kisor AK, Zhou H, Lara LM, Homer ML (2009) Operation of Third Generation JPL Electronic Nose on the International Space Station. SAE Technical Paper 2009-012522

Satoh, K, Nishiyama Y, Yamazaki T, Sugita T, Tsukii Y, Takatori K, Benno Y, Makimura K (2011) Microbe-I: fungal biota analyses of the Japanese experimental module KIBO 


\section{Reidt et al. -- Electric Nose Detects Microorganisms on ISS}

of the International Space Station before launch and after being in orbit for about 460 days. Microbiology and Immunology 55: 823-829

Viktorov AN, Novikova ND, Deshevaia EA (1992) The cabin microflora of manned space vehicles and the problem of the biological destruction of the construction materials used in them. Aviakosmicheskaia i Ekologicheskaia Meditsina 26: 41-48
White T, Bruns T, Lee S, Taylor J (1990) Amplification and direct sequencing of fungal ribosomal RNA genes for phylogenetics. In PCR Protocols: a guide to methods and applications, DH Gelfand and SJ White (eds), pp. 315-322. New York: Academic Press

Wilkins K, Larsen K, Simkus M (2000) Volatile metabolites from mold growth on building materials and synthetic media. Chemosphere 41: 437-446 